\title{
Integration of supercapacitors with enzymatic biobatteries toward more effective pulse-powered use in small-scale energy harvesting devices
}

\author{
Magdalena Skunik-Nuckowska • Katarzyna Grzejszczyk • \\ Krzysztof Stolarczyk · Renata Bilewicz • \\ Pawel J. Kulesza
}

Received: 31 July 2013/Accepted: 11 December 2013/Published online: 4 January 2014

(C) The Author(s) 2014. This article is published with open access at Springerlink.com

\begin{abstract}
Effective integration of electrochemical devices consisting of enzyme-based biobatteries together with high power double-layer type capacitors is discussed here. An ultimate goal is to overcome a typical drawback of enzymatic power sources (biofuel cells and biobatteries): although their energy is potentially high enough to fulfill the needs of small electronic devices, their power is often too low. It is demonstrated that properly selected capacitor can support operation of such a low power device simply by supplying appropriate power pulses with fast dynamic response that is required for many applications involving fluctuating loads. Our model integrated system is obtained by coupling a series of double-layer capacitors with wellbehaved zinc/oxygen biobattery. The biobattery utilizes a stable cathodic material composed of covalently phenylated single-walled carbon nanotubes and the oxygen reduction enzyme, laccase, together with the hopeite-covered zinc rod acting as the anode. The enzymatic power source was characterized by the maximum power density of $1.8 \mathrm{~mW} \mathrm{~cm}^{-2}$, the open circuit voltage of $1.6 \mathrm{~V}$. Nevertheless, under the $50 \Omega$ loading, the voltage of biobattery (electrode surface areas of ca. $0.3 \mathrm{~cm}^{2}$ ) drops to $0 \mathrm{~V}$ after $2 \mathrm{~s}$. The practical performance (power stability) of a biobattery has significantly improved by its parallel connection to electrochemical capacitor. The importance of such capacitor's parameters as low resistance (not more than a few hundred of milliohms), proper capacitance, and
\end{abstract}

\footnotetext{
M. Skunik-Nuckowska $(\bowtie) \cdot$ K. Grzejszczyk · K. Stolarczyk

R. Bilewicz · P. J. Kulesza $(\square)$

Department of Chemistry, University of Warsaw, Pasteura 1, 02-093 Warsaw, Poland

e-mail: mskunik@chem.uw.edu.pl

P. J. Kulesza

e-mail: pkulesza@chem.uw.edu.pl
}

leakage current (not higher than a few microamperes) is emphasized here. The potential utility of the optimized biobattery/supercapacitor system is discussed in terms of use as a source of power to operate a digital watch.

Keywords Integrated electrochemical system - Doublelayer capacitor · Biobattery $\cdot$ Carbon nanotubes $\cdot$ Laccasebased cathode $\cdot$ Zinc anode $\cdot$ Enzymatic power devices

\section{Introduction}

During recent years, various enzymatic energy sources have attracted broad attention as cost effective and environmentally friendly alternatives for such energy conversion technologies as fuel cells and secondary batteries [17]. The energy produced during electrochemical processes occurring in the enzymatic cell (biofuel cell) is generally high enough to power small portable devices. Moreover, the presence of natural biological substances active in the $\mathrm{pH}$ close to neutral and operation in ambient temperatures allows for their direct implementation into the living organisms [3]. The energy produced in a typical biofuel cell originates from redox reactions involving the oxygen reduction (at cathode) and oxidation of such an organic fuel as glucose or ethanol (at anode). More recently, there has been growing interest in hybrid biofuel cells known as biobatteries that are expected to produce higher open circuit potentials and power densities in comparison to the conventional biofuel cells [8-11]. The whole concept of operation of so called non-rechargeable zinc-air batteries is based on simultaneous oxidation of zinc at the battery-type anode and the oxygen reduction at the enzymatic cathode.

There have been a number of enzymatic systems considered for construction of cathodes in both biofuel cells 
and biobatteries [12-14]. It is commonly accepted that the most promising results are obtained with use of multicopper oxidases, among which the simplest oxidase, laccase, has been probably the most intensively studied due to its ability to catalyze effectively the reduction of oxygen directly to water at relatively low overpotentials $[8-11,15-$ 18]. Since proteins are macromolecules of largely developed and entangled structures, in which the catalytic centers are hidden inside the hydrophobic pocket, the distance between the enzyme's active center and the surface of electrode is usually too large for unimpeded direct transfers of electrons. To address this problem, various concepts for effective charge transfer mediation have been proposed $[15,19,20]$. It is noteworthy that, relative to many other enzymes, the laccase's active copper center is situated relatively close to the protein surface (ca. $0.7 \mathrm{~nm}$ ); consequently, the development of mediator-free laccase-based materials capable of operating according to the direct electron transfer (DET) mechanism is feasible [21-24]. A promising approach has utilized single-walled carbon nanotubes (SWNTs) modified with anthraquinone and anthracene groups on the sides or at the ends of the nanotubes as novel materials permitting DET in the laccase containing catalytic films. Under such conditions, the 2D type electrode structure is transferred into the 3D assembly characterized by the effectively high enzyme population directly connected to the electrode thus leading to increase of the oxygen reduction currents. Such cathodes have been tested in hybrid biobatteries and produced the power density exceeding $2 \mathrm{~mW} \mathrm{~cm}^{-2}$ and the open circuit potential equal to $1.5 \mathrm{~V}$ [9].

Physicochemical stability of the biobatteries is generally sufficient enough to insure good operation under moderately high loads. Using a representative example [25], a biobattery maintained the voltage on a level of $0.6-0.8 \mathrm{~V}$ under $2.2 \mathrm{k} \Omega$ load for several days. But, many electronic devices (e.g., portable music players, watches, wireless communication systems, medical equipment), even if designed on small-scale, require power demands changing drastically with operating mode. Having in mind a rather small power density offered by enzymatic systems (at best on the level of few $\left.\mathrm{mW} \mathrm{cm} \mathrm{cm}^{-2}[8,9,11]\right)$, it is reasonable to expect that a typical biobattery would not be able to deliver current pulses required for certain applications. Further, higher loads may lead to significant reduction of the biobattery lifetime or, even, to the performance failure and irreversible damage.

Electrochemical capacitors (supercapacitors) are often selected as power supports for various energy devices that include secondary batteries [26-30] and fuel cells [31-35], but, except a preliminary study [36], they have been barely so far considered as complementary power units coupled with enzymatic power sources. Electrochemical supercapacitors offer important features including high specific power (up to $1 \mathrm{~kW} \mathrm{~kg}{ }^{-1}$ ), allowing for large amount of energy to be delivered in a short period of time at low cost per cycle and great durability [37-40]. Representative examples include simple systems starting from porous carbon-based doublelayer capacitors [38, 41-44] to more complicated ones utilizing redox materials [45-48]. Having in mind high power applications, the capacitors involving only double-layer charging/discharging seem to be preferred due to their low internal resistance (on the level of milliohms), high output power, and fairly long lifetimes. When it comes to pulse power applications, the main drawback is in their high rate of self-discharge occurring as a side effect known as leakage current. This phenomenon, i.e., gradual loss of energy by a charged supercapacitor, will be considered here as the main limitation complicating application of supercapacitor as a device supporting operation of enzymatic power sources.

In the present work, we explore a biobattery utilizing the laccase-type-modified cathode, nanostructured with SWNTs terminally modified with phenyl groups, as active material toward oxygen reduction. A zinc rod covered with a protective film of $\mathrm{Zn}_{3}\left(\mathrm{PO}_{4}\right)_{2}$ (impermeable to oxygen) is used as the anode. The resulting biobattery is examined (alone or in parallel connection to a series of double-layer supercapacitors) under the high load regimes. Obviously the biobattery is a main source of energy, whereas the capacitor serves as an auxiliary one. Among the important supercapacitors' features is its ability to undergo fast charging/discharging so that high current may be delivered in a short time (milliseconds up to a few seconds). The supercapacitor would release its energy when the external device powered by a biobattery begins its operation, particularly when it requires a "peak current" to activate some of its functions or to change the operating mode (while a biobattery could be in a standby position). When it comes to potential applications (e.g., powering of the $1.5 \mathrm{~V}$ electronic watch), the choice of such capacitor's parameters as its capacitance, equivalent series resistance, and self-discharge rate should be carefully taken into consideration when a hybrid system is formed.

\section{Experimental}

\subsection{Materials preparation}

The Cerrena unicolor C-139 laccase samples lyophilized in vials were obtained from Prof. Rogalski (Department of Biochemistry, Maria Curie-Sklodowska University, Lublin, Poland), and they were isolated as described earlier [49]. The laccase stock solution activity determined after dissolving the protein powder (from vial) in $1 \mathrm{ml}$ of MilliQ water was equal to $250 \mathrm{U} \mathrm{mg}^{-1}$ of protein. 
The nanotubes modified with phenyl group on the endwalls (SWCNTs-PHEN-end) were obtained from Prof. Biernat and Dr. Zelechowska from Gdansk University of Technology, and they were synthesized as before [50].

\subsection{Biobattery—assembly procedure}

Biocathode The active layer was prepared on glassy carbon (GC) electrode (surface area, 0.07 or $0.28 \mathrm{~cm}^{2}$ ) which was initially polished using $0.05 \mu \mathrm{m}$ alumina slurry (Buehler, USA) on polishing cloth. In the first step, the electrode was covered with ink-type suspension containing phenylated SWCNTs (4 mg of SCWNTs in $1 \mathrm{ml}$ of $99.8 \%$ ethanol) until the loading was equal to $570 \mu \mathrm{g} \mathrm{cm}^{-2}$. The enzyme containing matrix was prepared by mixing the laccase solution (prepared by dissolving of $1 \mathrm{mg}$ of enzyme in $1 \mathrm{ml}$ of Mcllvaine buffer/ $0.2 \mathrm{~mol} \mathrm{dm}^{-3} \mathrm{NaNO}_{3}, \mathrm{pH}$ 5.2) and $1 \% \mathrm{Nafion}^{\mathrm{TM}}$ solution (prepared by mixing of $5 \%$ Nafion $^{\mathrm{TM}}$ solution from Sigma Aldrich with $99.8 \%$ ethanol). The volume ratio was $1: 1$. Further, the 10 and $40 \mu \mathrm{l}$ samples of thus obtained mixtures were dropped onto GC electrodes (of the areas, 0.07 and $0.28 \mathrm{~cm}^{2}$, respectively); and they were allowed to dry under ambient conditions.

Bioanode The zinc rod (diameter $6 \mathrm{~mm}$; from Merck, Germany) was at first dipped into $0.5 \%$ of Nafion ${ }^{\mathrm{TM}}$ in isopropanol $(99.7 \%)$ and let to dry. Thus, overcoated rod was further oxidized in the solution of $0.1 \mathrm{~mol} \mathrm{dm}^{-3}$ phosphate buffer ( $\mathrm{pH}$ 7) containing $0.15 \mathrm{~mol} \mathrm{dm}^{-3} \mathrm{NaCl}$ by application of a constant current of $13 \mathrm{~mA} \mathrm{~cm}^{-2}$ for $15 \mathrm{~h}$. This step led to the formation of stable and wellconductive hopeite layer $\left(\mathrm{Zn}_{3}\left(\mathrm{PO}_{4}\right)_{2}\right.$ protecting the anodic material against corrosion in contact with the oxygen-saturated electrolyte [51]. The surface area of bioanode being in contact with the electrolyte was each time adjusted by wrapping the zinc rod with Teflon ${ }^{\mathrm{TM}}$ tape to obtain the same surface of both (biocathode and bioanode) electrodes, namely 0.07 or $0.28 \mathrm{~cm}^{2}$.

\subsection{Electrochemical characterization of capacitors}

Two types of double-layer electrochemical capacitors were tested. They were commercially available activated carbonbased supercapacitors from Cellergy operating in aqueous electrolyte and characterized by the following parameters: capacitance $C=25 \mathrm{mF}$, operating charge/discharge voltage $U=3.5 \mathrm{~V}$, equivalent series resistance ESR $=300 \mathrm{~m} \Omega$, and leakage current $i_{\text {leakage }}=2 \mu \mathrm{A}$, as well as Swagelok-type cells built of multi-walled carbon nanotubes (MWCNTs) pellets $(1 \mathrm{~cm}$ in diameter) containing $90 \mathrm{wt} \%$ MWCNTs (Aldrich), $5 \mathrm{wt} \%$ acetylene black (Alfa Aesar), and $5 \mathrm{wt} \%$ PVDF (Aldrich) separated by glassy fibrous separator
(Aldrich) and immobilized between stainless steel current collectors. $1 \mathrm{~mol} \mathrm{dm}^{-3} \mathrm{H}_{2} \mathrm{SO}_{4}$ served as electrolyte. Two cells were further connected in series to increase the operating voltage. Finally, the following parameters were obtained: $C=100 \mathrm{mF}, U=1.6 \mathrm{~V}, \mathrm{ESR}=800 \mathrm{~m} \Omega$, and $i_{\text {leakage }}=$ $120 \mu \mathrm{A}$. Additionally, in some of the tests, the commercial Cellergy capacitors were connected in parallel to increase the capacitance.

\subsection{Instrumentation and electrochemical measurements}

Electrochemical characterization was carried out using $\mathrm{CH}$ 660C Workstation (Austin, TX, USA) and digital multimeter with computer-based interface (Appa, Taiwan). All electrochemical measurements were done at $22 \pm 2{ }^{\circ} \mathrm{C}$. The current and power densities were expressed against geometrical area of the electrode.

Parameters of supercapacitors were evaluated from galvanostatic, amperometric, and impedance data. To determine the capacitance, the cells were galvanostatically charged to $1.6 \mathrm{~V}$ and then discharged to $0 \mathrm{~V}$ at constant current. The capacitance was calculated according to the formula: $C=I t / U$, where $I$ stands for the discharge current (A), $t$ is the discharge time (s), and $U$ is the discharge voltage $(\mathrm{V})$. The equivalent series resistance was evaluated from the impedance Nyquist plots, namely from the intercept of the plot with the real axis, while the leakage current was obtained by charging the cells to $1.6 \mathrm{~V}$ for $2 \mathrm{~h}$ and, then, by measuring the current. Under the constant voltage conditions, the current flowing through the supercapacitor compensates the current leaking from the cell, and these parameters can be correlated with further selfdischarge problems.

Electrocatalytic properties of the biocathode were investigated using the three-electrode arrangement utilizing $\mathrm{Hg} / \mathrm{Hg}_{2} \mathrm{Cl}_{2}$ ( $\mathrm{KCl}$ sat.) reference electrode, $\mathrm{GC}$ rod as the counter electrode, and GC disk (CHI, USA) as the working electrode (surface area of $0.07 \mathrm{~cm}^{2}$ ).

The biobattery parameters were determined in the oxygen-saturated $0.1 \mathrm{M}$ McIlvaine buffer solution ( $\mathrm{pH}$ 5.2) modified by the addition of $0.2 \mathrm{~mol} \mathrm{dm}{ }^{-3}$ of $\mathrm{NaNO}_{3}$. The cell voltage was measured under the open circuit conditions, as well as under various loads ranging from $10 \mathrm{M} \Omega$ to $0.2 \mathrm{k} \Omega$. The voltage was recorded after $5 \mathrm{~s}$ following application of each load.

To comment on influence of the presence of supercapacitor on the power output of the biobattery, the zincoxygen power source alone, or in parallel connection with supercapacitor (or series of supercapacitors), was subjected to a continuous pulse work under the 200 or $50 \Omega$ load (depending on the biobattery's electrode surfaces). The pulse time was $2 \mathrm{~s}$. 


\section{Results and discussion}

\subsection{Electrocatalytic properties of SWCNTs-PHEN- end/laccase system toward $\mathrm{O}_{2}$ reduction}

In order to investigate the electrocatalytic activity of the cathodic material (used for the construction of the biobattery), a series of voltammetric experiments were conducted. Figure 1 illustrates responses of GC electrode modified with terminally phenylated SWNTs covered with a matrix containing laccase dispersed in Nafion ${ }^{\mathrm{TM}}$ solution. The final concentration of Nafion ${ }^{\mathrm{TM}}$ in the mixture was $0.5 \%$. The responses were recorded in the absence, i.e., in the nitrogen-saturated solution (Fig. 1a), and in the presence of oxygen (Fig. 1b). The onset potential (determined at $1 \mathrm{mV} \mathrm{s}^{-1}$ ) for the electrocatalytic process was equal to $0.58 \mathrm{~V}$ (vs. $\mathrm{Hg} / \mathrm{Hg}_{2} \mathrm{Cl}_{2}$ ), and the current density (measured at $0.15 \mathrm{~V}$ ) was equal to $395 \mu \mathrm{A} \mathrm{cm} \mathrm{cm}^{-2}$. The latter value was approximately twice higher than that reported earlier for the system utilizing SWNTs phenylated on the side walls [9]. The results were highly reproducible (within $5 \%$ ) during at least ten independent experiments.

\subsection{Electrochemical characterization of biobattery}

The electrode was further tested within the hybrid biobattery equipped with hopeite-covered $\mathrm{Zn}$ rod acting as an anode. The power density-voltage and the current density-voltage dependencies were plotted against external loads applied between the anode and the cathode (from $10 \mathrm{M} \Omega$ to $0.2 \mathrm{k} \Omega$ ). To minimize the power losses due to the oxygen depletion during the tests, the resistance pulses were each time limited

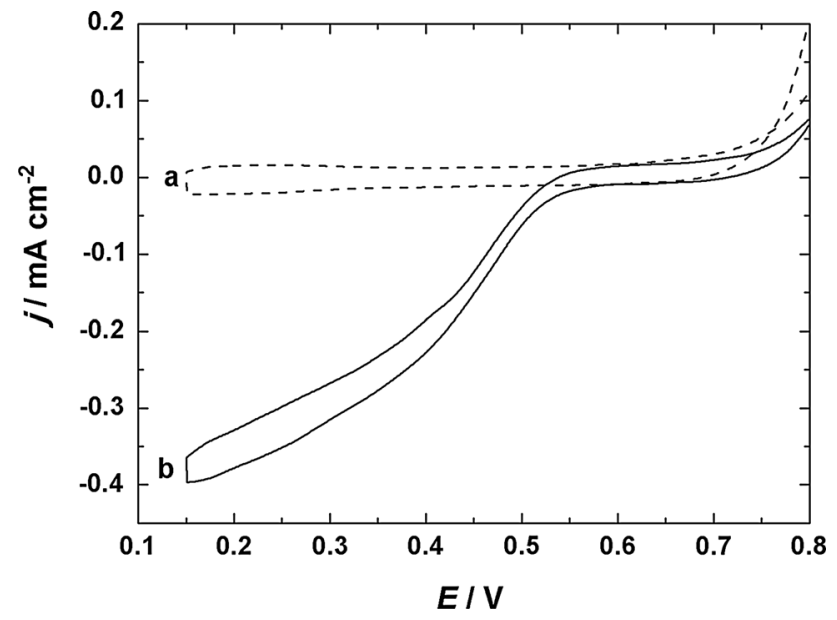

Fig. 1 Cyclic voltammetric response of GC electrode modified with phenylated SWCNTs (SWNTs-PHEN-end) and covered with Nafion $^{\mathrm{TM}} /$ laccase matrix recorded in $(a)$ deoxygenated, $(b)$ saturated with oxygen McIlvaine buffer/0.2 mol dm ${ }^{-3} \mathrm{NaNO}_{3}$ (pH 5.2). Scan rate: $1 \mathrm{mV} \mathrm{s}^{-1}$. Electrode surface: $0.28 \mathrm{~cm}^{2}$ to $5 \mathrm{~s}$. The results are presented in Fig. 2a. The open circuit voltage measured for the system before the load application was equal to $1.65 \mathrm{~V}$. The maximum power density of ca. $0.5 \mathrm{~mW}\left(1.8 \mathrm{~mW} \mathrm{~cm}^{-2}\right)$ was achieved under the load of $1 \mathrm{k} \Omega$ at the voltage of $0.7 \mathrm{~V}$ (Fig. 2b). Such low level of power density is a serious limiting factor when it comes to applications of the enzymatic energy sources requiring high current bursts. As it is apparent from Fig. 2a (green plot), the higher the output current, the lower voltage output was produced by the biobattery. For example, the current of $1.1 \mathrm{~mA}$ (ca. $4 \mathrm{~mA} \mathrm{~cm}^{-2}$ ) drained from the system causes a drastic voltage drop from $1.65 \mathrm{~V}$ down to $0.2 \mathrm{~V}$ thus precluding practical application of the biobattery. To keep biobattery at the maximum power output conditions (Fig. 2a, blue plot), the output current cannot exceed $0.7 \mathrm{~mA}\left(2.5 \mathrm{~mA} \mathrm{~cm}^{-2}\right)$. The discussed parameters significantly change when the system operates for longer periods of time. The likely features such as oxygen depletion
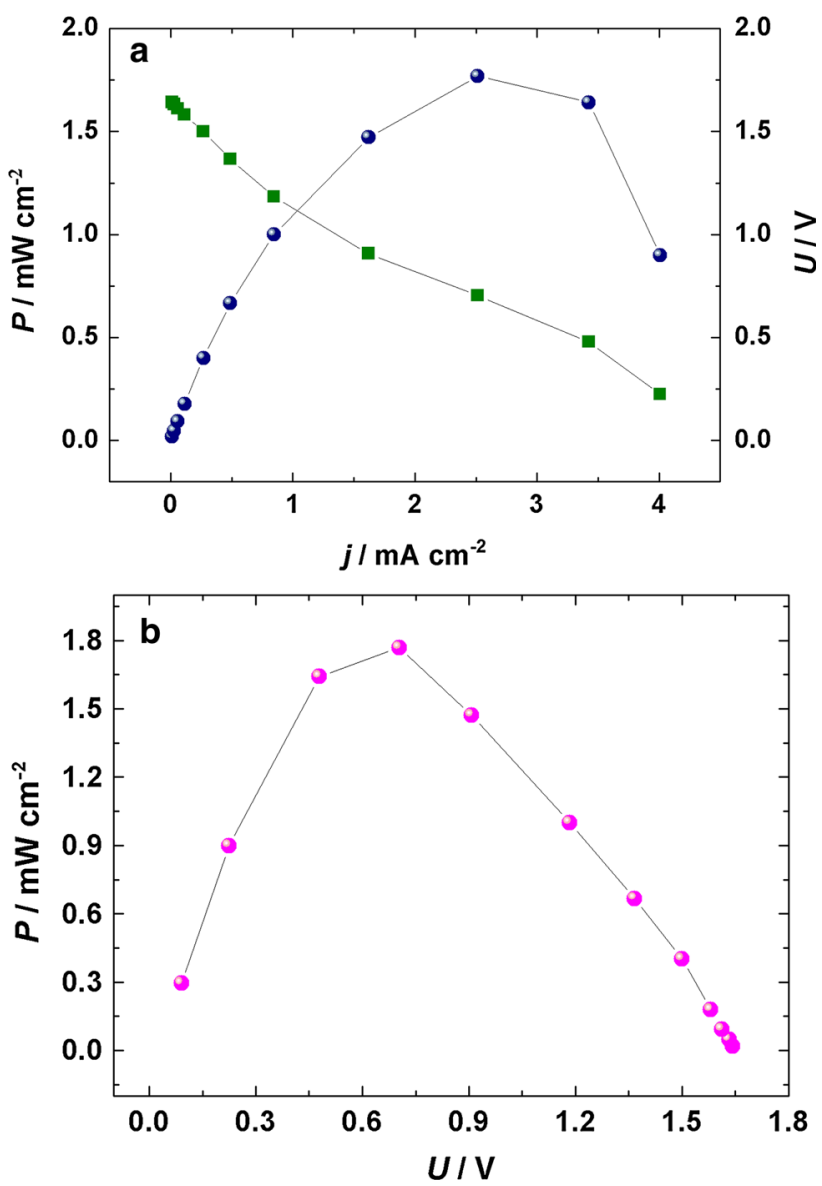

Fig. 2 Dependence of power density (blue coloured filled circle) and cell voltage (filled square) on current density (a) and power density (pink coloured filled circle) on cell voltage (b) plotted for laccasebased zinc-oxygen biobattery built of $\mathrm{Zn} / \mathrm{Zn}_{3}\left(\mathrm{PO}_{4}\right)_{2}$ anode and SWCNTs-PHEN-end/laccase/Nafion ${ }^{\mathrm{TM}}$ cathode. Electrolyte: oxygensaturated McIlvaine buffer/ $0.2 \mathrm{~mol} \mathrm{dm}{ }^{-3} \mathrm{NaNO}_{3}$ (pH 5.2). Electrode surfaces: $A=0.28 \mathrm{~cm}^{2}$ 


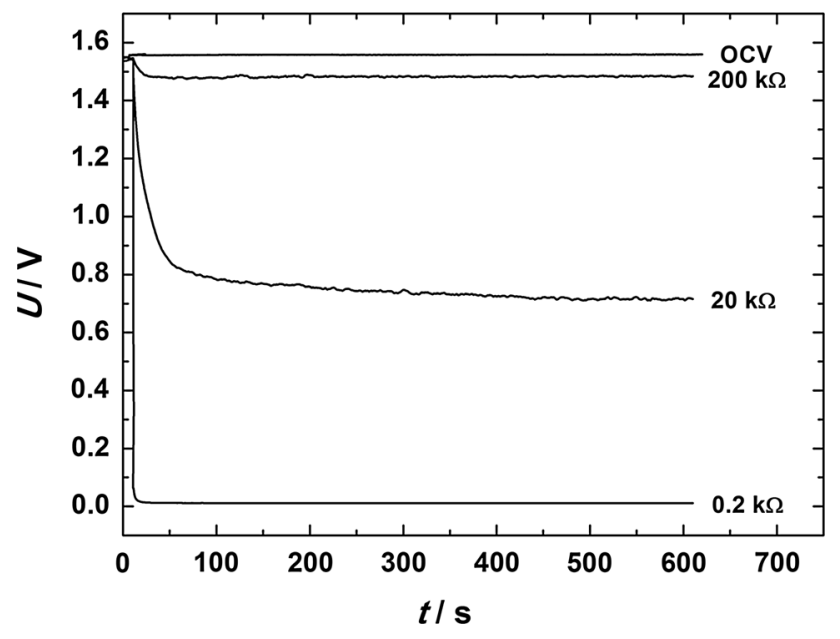

Fig. 3 Voltage-time dependence recorded for laccase-based zincoxygen biobattery operating in open circuit voltage conditions (OCV) as well as during application (600 s) of resistances: $0.2,2$, and $20 \mathrm{k} \Omega$. Electrode surfaces: $A=0.07 \mathrm{~cm}^{2}, P_{\max }=0.13 \mathrm{~mW}$. Electrolyte: oxygen-saturated McIlvaine buffer/0.2 mol dm${ }^{-3} \mathrm{NaNO}_{3}$ (pH 5.2)

occurring near the electrode surface or kinetic limitations in the cathodic reaction would lead to the further drop of voltage as demonstrated in Fig. 3. For all external loads applied, the steady-state voltage is readily reached, and this behavior refers to the real behavior of biobattery under standby conditions. Using the data of Fig. 3, the steady-state current recorded after $600 \mathrm{~s}$ of the biobattery's operation has been found to be equal to: $0.1 \mathrm{~mA} \mathrm{~cm}^{-2}$ at $20 \mathrm{k} \Omega$, $0.5 \mathrm{~mA} \mathrm{~cm}^{-2}$ at $2 \mathrm{k} \Omega$, and $0.7 \mathrm{~mA} \mathrm{~cm}^{-2}$ at $0.2 \mathrm{k} \Omega$. Obviously the current recorded upon application of the lowest resistance is the highest, nevertheless, the corresponding voltage tends to drop to $0 \mathrm{~V}$ thus making the biobattery useless while operating under conditions of such loads.

To elucidate the biobattery behavior under conditions demanding peak currents, the device was subjected to a series of short ( $2 \mathrm{~s}$ each) loads (200 $\Omega$ "pulses") for $7 \mathrm{~h}$. The results are shown in Fig. 4. It can be observed that, at the beginning of diagnostic tests, the open circuit voltage was equal to $1.63 \mathrm{~V}$, but it immediately dropped down to almost $0 \mathrm{~V}$ after each pulse. Thus, in practice, virtually any device powered by the biobattery would be practically switched off. Obviously, the current could be continuously produced by the cell as a result of electrochemical reactions, and the voltage recovery would be expected in ca. $20 \mathrm{~min}$. We noticed that the continuous pulse operation led to a slow and gradual decrease in the initial value of voltage available under open circuit conditions, most probably due to the irreversible degradation of the enzyme structure caused by application of high external loads.

The above results are consistent with the view that biobatteries are not suitable devices for operation when high power pulses are required. This problem can be solved

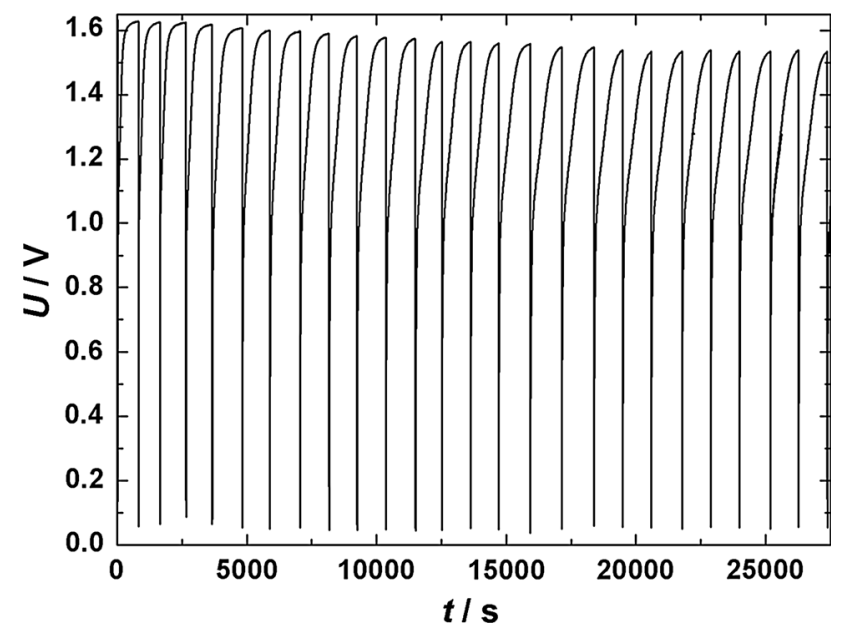

Fig. 4 Variation of laccase-based zinc-oxygen biobattery voltage versus time upon application of external loads of $200 \Omega$ for $2 \mathrm{~s}$. Electrode surfaces: $A=0.07 \mathrm{~cm}^{2}, P_{\max }=0.13 \mathrm{~mW}$. Electrolyte: oxygen-saturated McIlvaine buffer/ $0.2 \mathrm{~mol} \mathrm{dm}{ }^{-3} \mathrm{NaNO}_{3}$ (pH 5.2)

in two ways: either (i) by the increase of the electrodes surface area or (ii) by combining biobattery with external high power device. The first solution is rather difficult to realize, because modern electronic devices are intended to be miniaturized. With respect to the second solution, we refer here to the earlier study [36] describing the data concerning integration of enzymatic biobattery with two electrochemical capacitors connected in series. The resulting hybrid system was subjected every $20 \mathrm{~min}$ to high current pulses of $5 \mathrm{~mA}$ each lasting for $3 \mathrm{~s}$. Integration with high power supercapacitors led to stabilization of the voltage output of biobattery on the constant level of ca. $1.1 \mathrm{~V}$ for $35 \mathrm{~h}$. Obviously, the choice of such supercapacitor's parameters as resistance, capacitance, and leakage current is crucial to successful operation of the hybrid system. Our observations and recommendations are discussed in the next section.

\subsection{Enhancement of biobattery's power level through combination with supercapacitor}

Figure 5 illustrates a hybrid system obtained by integrating the zinc-oxygen biobattery with the carbon/carbon doublelayer type electrochemical capacitor. The capacitor was placed in parallel to the biobattery, and it was connected to the resistance decade simulating various external loads. To monitor and control passing current and generated voltage, potentiostat and multimeter were also included in the network. The switch between the biobattery and supercapacitor allows for quick connection/disconnection of supercapacitor.

High internal resistance is one of the key factors responsible for the low power output of enzymatic 
biobattery. The resistive limitations may originate from the ohmic resistance of electrolyte or electrode materials, the mass transport resistance, and, predominantly, from the charge transfer resistance assigned to the slow kinetics of bioelectrochemical reactions [52]. Thus, there is need for a low internal resistance supercapacitor to be used as an auxiliary device supporting possible higher power applications. Generally, the lower the capacitor's resistance, the lesser the restrictions in its ability to act as an effective supporting device. The carbon/carbon supercapacitors utilized by us were characterized by acceptable resistances on the level of milliohms. In particular, the resistances were on the level of ca. to $300 \mathrm{~m} \Omega$ for a single commercial cell and $400 \mathrm{~m} \Omega$ for single Swagelok-type cell utilizing MWCNTs. At the operating voltage of $1.6 \mathrm{~V}$, the maximum power of the supercapacitor was calculated according to the formula:

$P_{\max }=\frac{U^{2}}{4 \mathrm{ESR}}$

where $P_{\max }$ is the maximum power, and other parameters have been described earlier. The maximum power values determined for the investigated cells were in the range from 0.8 to $2.1 \mathrm{~W}$ depending on the cell type and assembly (i.e., connection in parallel or in series). Obviously, the resistance was doubled when two supercapacitors were connected in series aiming at increasing the system's overall voltage output (e.g., the case of Swagelok-type cells

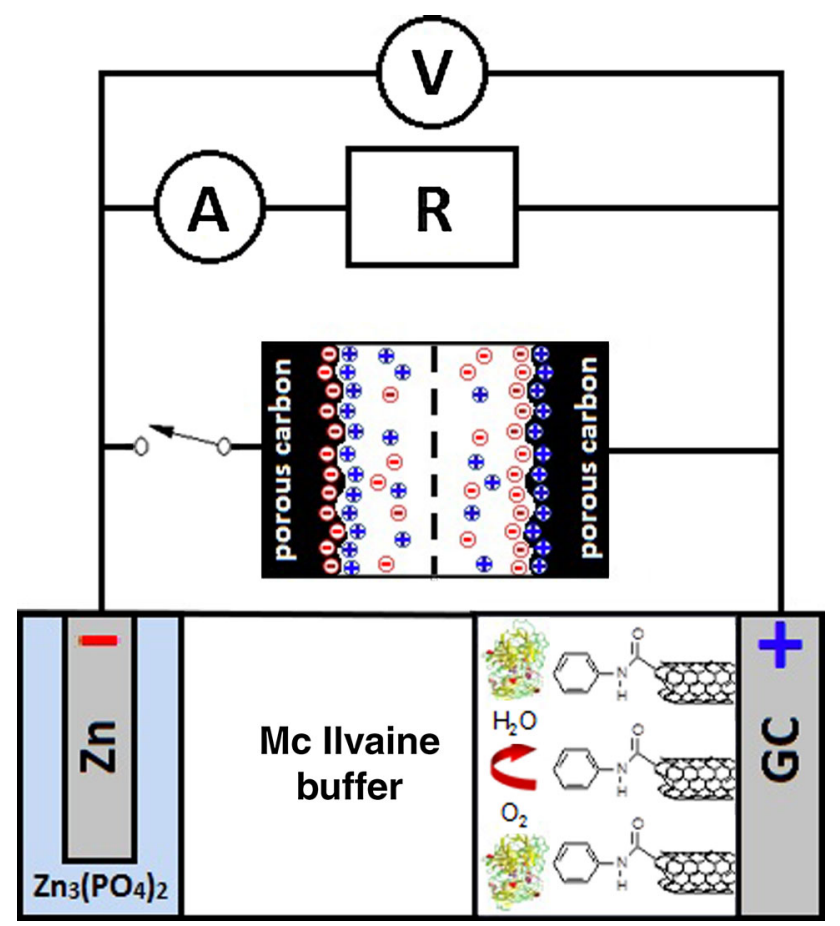

Fig. 5 Schematic representation showing the connection and operation rules of integrated laccase-based zinc-oxygen biobattery and supercapacitor
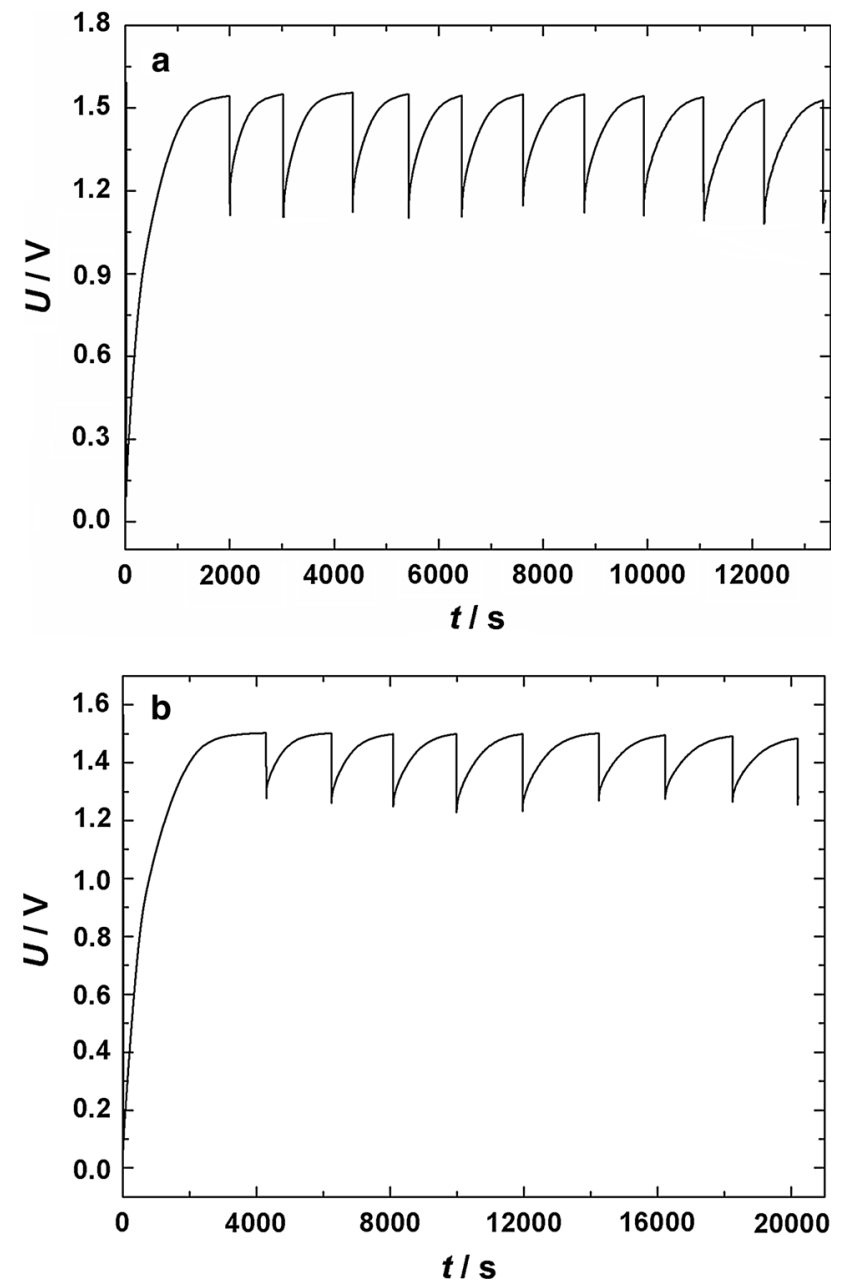

Fig. 6 Voltage changes across $0.13 \mathrm{~mW}$ laccase-based zinc/oxygen biobattery (electrode surfaces: $A=0.07 \mathrm{~cm}^{2}$ ), connected in parallel to: a $25 \mathrm{mF}$, b $50 \mathrm{mF}$ supercapacitor recorded during application of external load of $200 \Omega$ for $2 \mathrm{~s}$

utilizing carbon nanotubes). Due to the relatively lower resistivity, double-layer type capacitors are preferred over redox-type capacitors for integration with such a low power device as biobattery.

As already mentioned, when the voltage drop across the biobattery (upon application of high external load) is too large, the device will not work properly. Figure 6 illustrates how the presence of supercapacitor influences the voltage-time characteristics. In the present study, the biobattery (with electrode surface areas of $0.07 \mathrm{~cm}^{2}$ ) was characterized by power of $0.13 \mathrm{~mW}$, and it was coupled with commercial carbon/carbon supercapacitors characterized by variable capacitances. Figures $6 a$ and $b$ show the potential $(U)$-time $(t)$ responses obtained for the $0.13 \mathrm{~mW}$ laccase-based zinc/oxygen biobattery connected in parallel with the 25 and $50 \mathrm{mF}$ supercapacitors (they were discharged to $0 \mathrm{~V}$ before connection to the circuit). The capacitance of $50 \mathrm{mF}$ was achieved by connecting two 
$25 \mathrm{mF}$ single cells in parallel. At the beginning, i.e., under open circuit conditions, the biobattery produced the maximum voltage of ca. 1.6 V. Once the circuit was closed, the biobattery started to deliver current to the discharged supercapacitor. The charging time was obviously dependent on the capacitance values, and within ca. 35 and $70 \mathrm{~min}$, the maximum voltages of 1.54 and $1.5 \mathrm{~V}$ were obtained for the biobattery systems connected with the 25 and $50 \mathrm{mF}$ supercapacitors (Fig. 6a, b), respectively.

In the next step, the external loads of $200 \Omega$ were applied for $2 \mathrm{~s}$ to the systems. For comparison, the $0.13 \mathrm{~mW}$ biobattery operating as a single device (Fig. 4) and subjected to such an extreme load responded with a rapid decrease of voltage from $1.6 \mathrm{~V}$ to almost $0 \mathrm{~V}$. In the presence of supercapacitors, the voltages were maintained on the levels of $1.1 \mathrm{~V}$ (Fig 6a) and 1.3 V (Fig. 6b). The differences in the observed voltage drops should be attributed to the different amounts of energy supplied by supercapacitors characterized by different capacitances. The amount of energy utilized depends on the power demand and the time for which the system is used according to the equation:

$P_{\text {load }}=\frac{E_{\text {cap }}}{t}$

where $E_{\text {cap }}$ is the energy provided by electrochemical capacitor, $P_{\text {load }}$ is the required power, and $t$ is the time during which the energy is delivered.

Having in mind the fact that supercapacitor's energy is directly proportional to its capacitance, it is reasonable to expect that during the same period of time $(2 \mathrm{~s})$, the $50 \mathrm{mF}$ supercapacitor would be able to deliver more power than the cell of smaller capacitance $(25 \mathrm{mF})$. Consequently, the utilization of $50 \mathrm{mF}$ capacitor should lead to a smaller voltage drop (Fig. 5b). Therefore, the capacitance should be adjusted to assure an energy balance that can be understood as follows:

$E_{\text {cap }}=E_{\text {load }}$

$\frac{1}{2} C_{\text {cap }}\left(U_{0}^{2}-U_{1}^{2}\right)=P_{\text {load }} \times t$

where $C_{\text {cap }}$ is the required capacitance, $U_{0}$ is the initial supercapacitor voltage, $U_{1}$ is the minimum voltage to which a supercapacitor can be discharged at the end of the peak load, and $E_{\text {load }}$ stands for the load energy that can be calculated as the required power $\left(P_{\text {load }}\right)$ multiplied by load duration $(t)$.

Having in mind the above considerations, the capacitance can be easily found as:

$C_{\text {cap }}=2 \frac{P_{\text {load }} \times t}{U_{0}^{2}-U_{1}^{2}}$

It is important to note that the Eq. 5 does not include the supercapacitor's resistance (ESR). Nevertheless, having in mind that supercapacitors are generally characterized by low equivalent series resistance, i.e., it can be assumed that ESR $\ll \mathrm{U}_{1}$, and, therefore, it can be typically neglected.

For more detailed characterization, the data of Figs. 4 and $6 \mathrm{~b}$ have been considered to comment on the energy and power capabilities during the system's operation for $2 \mathrm{~s}$ under the load of $200 \Omega$. Consequently, the biobattery/ supercapacitor hybrid system is characterized (vs. simple biobattery) by the following parameters: power, $8.5 \mathrm{~mW}$ (vs. $0.013 \mathrm{~mW}$ ); energy, $17 \mathrm{~mJ}$ (vs. $0.025 \mathrm{~mJ}$ ); and power capacity, $4.7 \mu \mathrm{Wh}$ (vs. $0.007 \mu \mathrm{Wh}$ ).

Considering the applications of supercapacitor as an auxiliary device for bioelectrochemical power sources and realizing that its task is to recharge the supercapacitor between the power pulses, the charging mechanism has been carefully investigated by us. When the circuit of Fig. 5 has been closed, the biobattery has started to deliver the current to discharging supercapacitor. Simultaneously, the current flowing through the circuit and the voltage produced were recorded. The results are presented in Fig. 7. The inset to Fig. 7 illustrates the charging characteristics (voltage-time dependence) for the $25 \mathrm{mF}$ supercapacitor connected in parallel to $0.13 \mathrm{~mW}$ laccase-based zinc-oxygen biobattery. The plot is nonlinear, and it is characteristic of the case involving charging at constant current. In other words, the current injected into the cell changes with time, and, therefore, the exponential-type response appears. This situation has been confirmed in the course of direct current measurements (Fig. 7a). As it can be seen, the current which is transferred from the biobattery reaches $0.1 \mathrm{~mA}$ at the beginning of charging (short circuit of the cells) and tends to decay rapidly with time. After ca. 2,000 s, the biobattery delivers only $13 \mu \mathrm{A}$

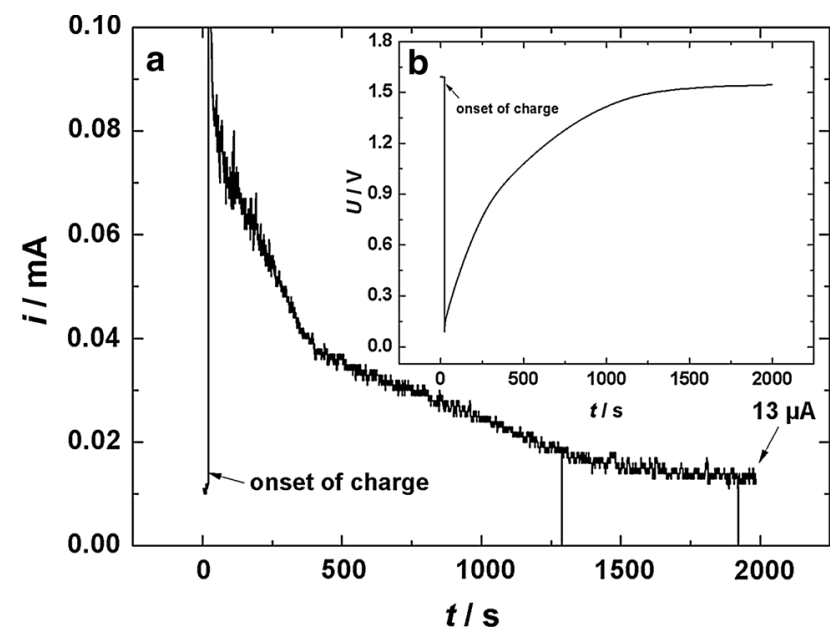

Fig. 7 Charging of $25 \mathrm{mF}$ supercapacitor by laccase-based zinc/ oxygen biobattery $(0.13 \mathrm{~mW})$ (electrode surfaces: $A=0.07 \mathrm{~cm}^{2}$ ). a monitoring of current flowing from biobattery to supercapacitor and b voltage changes in the circuit 


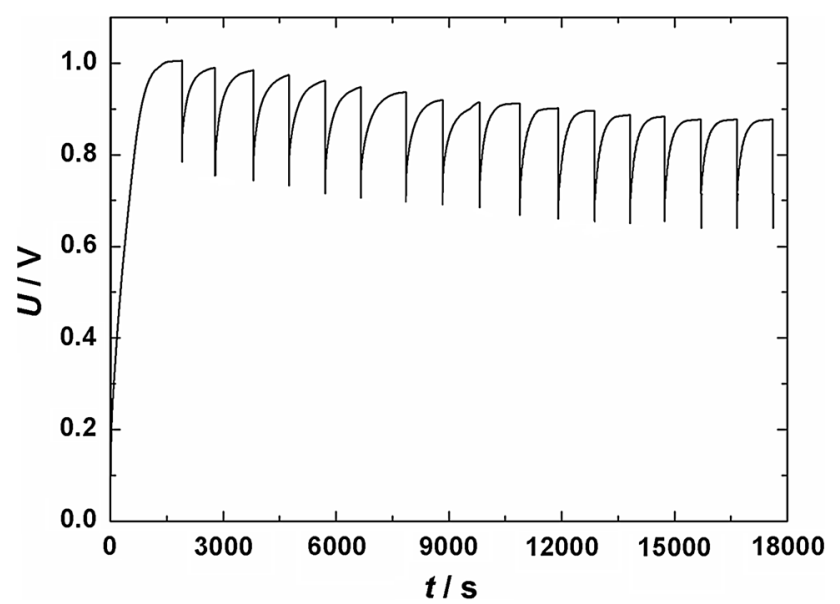

Fig. 8 Voltage changes across $0.5 \mathrm{~mW}$ laccase-based zinc/oxygen biobattery (electrode surfaces: $A=0.28 \mathrm{~cm}^{2}$ ) connected in parallel to $100 \mathrm{mF}$ Swagelok-type supercapacitor (two cells in series) recorded during application of external loads of $50 \Omega$ for $2 \mathrm{~s}$. Supercapacitor material: $90 \mathrm{wt} \%$ MWCNTs, $5 \mathrm{wt} \%$ acetylene black, and $5 \mathrm{wt} \%$ PVDF. Supercapacitor electrolyte: $1 \mathrm{~mol} \mathrm{dm}^{-3} \mathrm{H}_{2} \mathrm{SO}_{4}$

resulting in the saturation of the supercapacitor and in appearance of the almost steady-state voltage in the system (Fig. 7b). In the configuration considered by us, the final voltage is very close to the open circuit voltage of the biobattery itself, and it is equal to $1.55 \mathrm{~V}$. It should be attributed to the following features: (i) sufficiently low capacitance $(25 \mathrm{mF})$, and (ii) almost negligible leakage current $(2 \mu \mathrm{A})$. Our further deliberations will concentrate on the influence of these two factors on the performance of the biobattery/supercapacitor hybrid system.

Figure 8 refers to the operation of the $0.5 \mathrm{~mW}$ biobattery (electrode areas, $0.28 \mathrm{~cm}^{2}$ ) under the load of $50 \Omega$ but following connection to two Swagelok-type cells [38] utilizing multi-walled carbon nanotubes as electrode materials and operating in $1 \mathrm{~mol} \mathrm{dm}^{-3}$ sulfuric acid. The main goal of this study has been to show how the leakage current occurring in the cell affects performance of the integrated system. The self-discharge process induced by the leakage current is defined as a spontaneous and gradual voltage loss observed in the charged supercapacitor. The higher the leakage current, the faster the voltage decay will occur, thus resulting in overall power decrease. Generally, the leakage current can be produced as the effect of following processes: (i) electrochemical decomposition of the electrolyte (when the charging/discharging takes place beyond the thermodynamic potential window of the electrolyte), (ii) parasitic reactions related to the material's and electrolyte's impurities, (iii) presence of oxygen in the electrolyte and its reduction at the negative electrode, (iv) non-uniform distribution of charge within the deep pores of electrode material dependent on the pore structure and its geometry (regarded to be a predominant effect), and (v) the presence of short-circuits as a result of not sufficient isolation of electrodes [53]. When the supercapacitor is used together with enzymatic power source, the leakage current should be as low as possible. These requirements are much more severe than for other integrated systems including batteries or fuel cells and supercapacitors. To achieve an acceptable level of few $\mu \mathrm{A}$ (as in commercial supercapacitors used in our previous investigations), it is necessary to optimize the manufacturing procedures to insure the quality control and eliminate the parasitic factors. The carbon nanotubes-based supercapacitor used in our studies (Fig. 8) was characterized by the leakage current of $120 \mu$ A. Having in mind a very low output current supplied by the biobattery which expotentially decreases when the voltage across supercapacitor grows (Fig. 7), it is reasonable to expect that the rate of supercapacitor's leakage will be faster than the rate of charging. This phenomenon would result in incomplete charging which stops when the current produced by the biobattery reaches the value of the leakage current. For this reason, the maximum voltage obtained for the investigated system was equal to $1 \mathrm{~V}$ at the beginning of operation and had a tendency to decrease in time which can be attributed to the leakage current fluctuation or/and the biobattery aging. The problem with complete charging might also occur when the charge storage device used is characterized by too high capacitance. Assuming that the leakage current is on the level of few $\mu \mathrm{A}$, theoretically, the charging process should proceed without any difficulties. However, a very small amount of charge injected to the supercapacitor, additionally decreasing with time, could make the process extremely (unrealistically) time consuming.

To comment the potential utility of the proposed hybrid configuration, a $1.5 \mathrm{~V}$ electronic watch has been chosen as the device to be powered by $0.5 \mathrm{~mW}$ laccase-based zinc/ oxygen biobattery (electrode surface area, $0.28 \mathrm{~cm}^{2}$ ) connected in parallel to the $50 \mathrm{mF}$ (obtained by connection of two commercial carbon/carbon cells in parallel) low leakage current $(4 \mu \mathrm{A})$ supercapacitor in the circuit equipped with the switch allowing for quick connection and disconnection of supercapacitor. The power provided by a biobattery is high enough to operate the watch under standby or passive conditions, i.e., without using of any of its special functions. When the input current is equal to ca. $10 \mu \mathrm{A}$, only a slight voltage drop across the biobattery, namely from $1.6 \mathrm{~V}$ (labeled as 1 in Fig. 9a) to $1.57 \mathrm{~V}$ (labeled as 2 in Fig. 9a) has been observed. The stability test (Fig. 9b) shows that that the biobattery's operating voltage under standby conditions can be held at a constant level for $10 \mathrm{~h}$ while the measurements performed in air-saturated solution (not shown here) confirmed the good stability (voltage decay on the level of $5 \%$ ) during several days. However, when the watch is used in the different operating modes (light up, alarm) requiring higher input currents, the powered device has immediately switched off, because the biobattery was 
not able to maintain the required voltage (1.05-1.5 V). For example, the voltage drop occurring in the circuit following activation of the light up function for $2 \mathrm{~s}$ (marked as 3 ) is illustrated in Fig. 9a (navy-blue line). The system's voltage has immediately decreased to $0.6 \mathrm{~V}$, and it has occurred to be too low for further operation of the watch until the biobattery is recovered to at least $1.05 \mathrm{~V}$. In contrast, when the $50 \mathrm{mF}$ supercapacitor has been introduced to the circuit, the voltage drop following switching on the light up function is significantly lower [namely, it decreased to only $1.4 \mathrm{~V}$ during $2 \mathrm{~s}$ (Fig. 9a, pink line)]. When the light up function has been switched off, the biobattery has started to operate in the standby mode again (labeled as 4 in Fig 9a) permitting simultaneous recharging of the supercapacitor. Following $1,000 \mathrm{~s}$ of testing, the charged supercapacitor can be disconnected leaving the biobattery as the main power source for the watch. Although the positive effect of a supercapacitor on the power capability of a biobattery is unquestionable, it is noteworthy that the capacitor's presence somewhat limits supply of energy from the biobattery. This "overhead of hybridization" refers to the system's energy loss originating from the supercapacitor's leakage current that must be continuously compensated by the biobattery. Namely, $4 \mu \mathrm{A}$ is taken out from the biobattery during recharging of the supercapacitor as well as during holding its voltage at constant value while operating under standby condition. By taking into account proportionality of the leakage current to the terminal voltage of supercapacitor, the energy loss has obviously found to be lower at the lower voltage, but it is still on the level of $0.5-0.6 \mathrm{~mJ}$. To summarize, we demonstrate that coupling of the auxiliary storage device (supercapacitor) together with the enzymatic power source (biobattery) is of primary importance to its stable operation under conditions of the fluctuating loads (that would otherwise reduce the biobattery's performance during longer periods of time). Future research would require better control and minimizing of the current loss parameters of supercapacitors. These features are crucial to further development of bioelectrochemical energy sources that could operate in practice without energy losses and power deficiencies.

\section{Conclusions}

We demonstrate here that the combination of electrochemical capacitor together with biobattery can significantly improve the power performance of the enzymatic biobattery (that otherwise low power device) and, consequently, prolongs its practical life-time. As model enzymatic system, the wellbehaved mediator-free zinc/oxygen biobattery utilizing a GC electrode decorated with phenylated SWNTs/laccase and

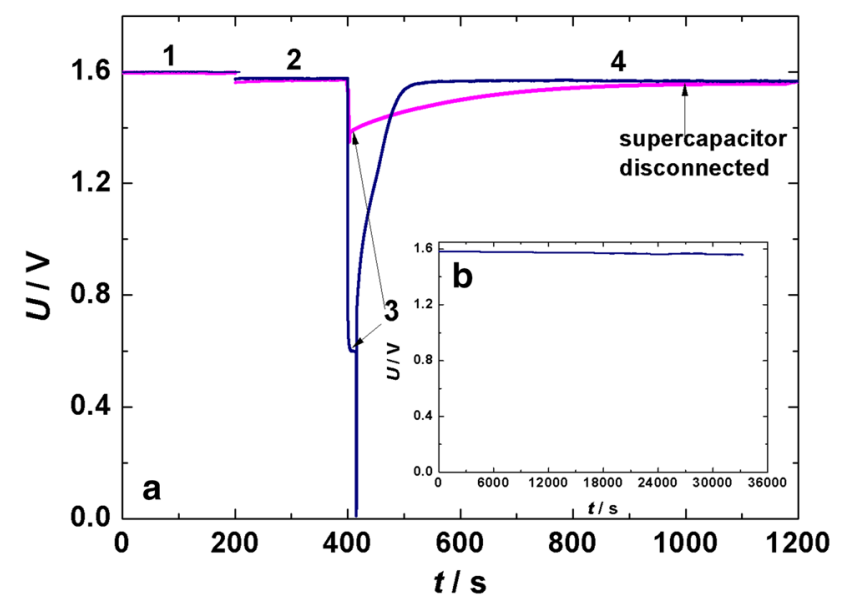

Fig. 9 a Voltage changes across $0.5 \mathrm{~mW}$ laccase-based zinc/oxygen biobattery used to run a digital watch recorded in standby conditions (labeled as 2 and 4) and during high input current mode (3) in the absence (navy-blue plot) and in the presence (pink plot) of $50 \mathrm{mF}$ supercapacitor in the circuit. Inset $b$ represents the voltage versus time dependence in standby conditions

$\mathrm{Zn}_{3}\left(\mathrm{PO}_{4}\right)_{2}$-covered zinc rod has been used. The biobattery itself has been characterized by high open circuit voltage exceeding $1.6 \mathrm{~V}$ and a power density of ca. $1.8 \mathrm{~mW} \mathrm{~cm}$. Although the power density has been found to be among the highest reported so far, its level is still insufficient for applications requiring high external loads: under such condition, the biobattery's voltage tends to rapidly drop to $0 \mathrm{~V}$. A conventional parallel connection with carbon/carbon doublelayer capacitor significantly reduced the output voltage loss by providing the necessary power peaks to the system. Our results are consistent with the view that, for the proper operation of the biobattery containing integrated system, the equivalent series resistance of supercapacitor should be on the level of a few hundred of $m \Omega$ and the leakage current should not exceed a few $\mu$ A. Furthermore, the capacitance has to be carefully selected to provide the required energy balance. Such optimized system has been found to be potentially suitable to power a digital watch under operating modes having different power demands. Our present results have preliminary character, but they seem to define directions for research aiming at the development of more practical enzyme-based biobatteries and biofuel cells.

Acknowledgments This work was supported by the Polish Ministry of Science and Higher Education and the National Center for Research and Development (NCBiR) under the project NR05-001710/2010 (PBR-11).

Open Access This article is distributed under the terms of the Creative Commons Attribution License which permits any use, distribution, and reproduction in any medium, provided the original author(s) and the source are credited. 


\section{References}

1. Tarasevich MR, Yaropolov AI, Bogdanovskaya VA, Varfolomeev SD (1979) Electrocatalysis of a cathodic oxygen reduction by laccase. Bioelectrochem Bioenergy 6:393-403

2. Eys JV, Kaplan NO (1957) Yeast alcohol dehydrogenase. III. Relation of alcohol structure to activity. J Am Chem Soc 79:2782-2786

3. Heller A (2004) Miniature biofuel cells. Chem Phys 6:209-216

4. Persson B, Gorton L, Johansson G, Torstensson A (1985) Biofuel anode based on D-glucose dehydrogenase, nicotinamide adenine dinucleotide and a modified electrode. Enzyme Microb Technol 7:549-552

5. Willner I, Arad G, Katz E (1998) A biofuel cell based on pyrroloquinolinequinone and microperoxidase-11 monolayer-functionalized electrodes. Bioelectrochem Bioenergy 44:209-214

6. Minteer SD, Liaw BY, Cooney MJ (2007) Enzyme-based biofuel cells. Curr Opin Biotechnol 18:228-234

7. Barton SC, Gallaway J, Atanassov P (2004) Enzymatic biofuel cells for implantable and microscale devices. Chem Rev $104: 4867-4886$

8. Jensen UB, Lorcher S, Vagin M, Chevallier J, Shipovskov S, Koroleva O, Besenbacher F, Ferapontova EE (2012) A 1.76 V hybrid $\mathrm{Zn}-\mathrm{O}_{2}$ biofuel cell with a fungal laccase-carbon cloth biocathode. Electrochim Acta 62:218-226

9. Stolarczyk K, Lyp D, Zelechowska K, Biernat JF, Rogalski J, Bilewicz R (2012) Arylated carbon nanotubes for biobatteries and biofuel cells. Electrochim Acta 79:74-81

10. Nazaruk E, Karaskiewicz M, Zelechowska K, Biernat JF, Rogalski J, Bilewicz R (2012) Powerful connection of laccase and carbon nanotubes: Material for mediator-free electron transport on the enzymatic cathode of the biobattery. Electrochem Commun 14:67-70

11. Stolarczyk K, Sepelowska M, Lyp D, Zelechowska K, Biernat JF, Rogalski J, Farmer KD, Roberts KN, Bilewicz R (2012) Hybrid biobattery based on arylated carbon nanotubes and laccase. Bioelectrochem 87:154-163

12. Karaskiewicz M, Nazaruk E, Zelechowska K, Biernat J, Rogalski J, Bilewicz R (2012) Fully enzymatic mediatorless fuel cell with efficient naphthylated carbon nanotube-laccase composite cathodes. Electrochem Commun 20:124-127

13. Zloczewska A, Jonsson-Niedziolka M (2013) Efficient airbreathing biocathodes for zinc/oxygen batteries. J Power Sources 228:104-111

14. Ferapontova EE (2006) In: Grimes CA, Dickey EC, Pishko MV (eds) Encyclopedia of sensors. American Scientific Publishers, Stevenson Ranch, p 391

15. Karnicka K, Miecznikowski K, Kowalewska B, Skunik M, Opallo M, Rogalski J, Schuhmann W, Kulesza PJ (2008) ABTSmodified multiwalled carbon nanotubes as an effective mediating system for bioelectrocatalytic reduction of oxygen. Anal Chem 80:7643-7648

16. Cardoso FP, Neto SA, Fenga PG, Ciancaglini P, de Andrade AR (2013) Electrochemical characterization of methanol/O2 biofuel cell: Use of laccase biocathode immobilized with polypyrrole film and PAMAM dendrimers. Electrochim Acta 90:90-94

17. Ding S-N, Holzinger M, Mousty C, Cosnier S (2010) Laccase electrodes based on the combination of single-walled carbon nanotubes and redox layered double hydroxides: Towards the development of biocathode for biofuel cells. J Power Sources 195:4714-4717

18. Jenkins $\mathrm{P}$, Tuurala $\mathrm{S}$, Vaari A, Valkiainen $\mathrm{M}$, Smolander M, Leech D (2012) A mediated glucose/oxygen enzymatic fuel cell based on printed carbon inks containing aldose dehydrogenase and laccase as anode and cathode. Enzyme Microb Technol 50:181-187

19. Barriere F, Ferry Y, Rochefort D, Leech D (2004) Targetting redox polymers as mediators for laccase oxygen reduction in a membrane-less biofuel cell. Electrochem Commun 6:237-241

20. Swietlikowska A, Gniadek M, Palys B (2013) Electrodeposited grapheme nano-stacks for biosensor applications. Surface groups as redox mediators for laccase. Electrochim Acta 98:75-81

21. Wang X, Latonen R-M, Sjoberg-Eerola P, Eriksson J-E, Bobacka J, Boer H, Bergelin M (2011) Direct electron transfer of trameteshirsutalaccase in a dual-layer architecture of poly(3,4-ethylenedioxythiophene) films. J Phys Chem C 115:5919-5929

22. Hussein L, Rubenwolf S, Stetten FV, Urban G, Zengerle R, Krueger M, Kerzenmacher S (2011) A highly efficient buckypaper-based electrode material for mediatorless laccase-catalyzed dioxygen reduction. Biosens Bioelectron 26:4133-4138

23. Vaz-Dominguez C, Campuzano S, Rudiger O, Pita M, Gorbacheva M, Shleev S, Fernandez VM, De Lacey AL (2008) Laccase electrode for direct electrocatalytic reduction of $\mathrm{O}_{2}$ to $\mathrm{H}_{2} \mathrm{O}$ with high-operational stability and resistance to chloride inhibition. Biosens Bioelectron 24:531-537

24. Ardhaoui M, Zheng M, Pulpytel J, Dowling D, Jolivalt C, Khonsar FA (2013) Plasma functionalized carbon electrode for laccase-catalyzed oxygen reduction by direct electron transfer. Bioelectrochem 91:52-61

25. Smolander M, Boer H, Valkiainen M, Roozeman R, Bergelin M, Eriksson J-E, Zhang X-C, Koivula A, Viikari L (2008) Development of a printable laccase-based biocathode for fuel cell applications. Enzyme Microb Technol 43:93-102

26. Choi SH, Kim J, Yoon YS (2004) Fabrication and characterization of a $\mathrm{LiCoO}_{2}$ battery-supercapacitor combination for a highpulse power system. J Power Sources 138:360-363

27. Cericola D, Ruch PW, Kotz R, Novak P, Wokaun A (2010) Simulation of a supercapacitor/Li-ion battery hybrid for pulsed applications. J Power Sources 195:2731-2736

28. Shin D, Kim Y, Wang Y, Chang N, Pedram M (2012) Constantcurrent regulator-based battery-supercapacitor hybrid architecture for high-rate pulsed load applications. J Power Sources 205:516-524

29. Decaux C, Lota G, Raymundo-Pinero E, Frackowiak E, Beguin F (2012) Electrochemical performance of a hybrid lithium-ion capacitor with a graphite anode preloaded from lithium bis(trifluoromethane)sulfonimide-based electrolyte. Electrochim Acta $86: 282-286$

30. Ghenaatian HR, Mousavi MF, Rahmanifar MS (2011) High performance battery-supercapacitor hybrid energy storage system based on self-doped polyaniline nanofibers. Synth Met 161:2017-2023

31. Park K-W, Ahn H-J, Sung Y-E (2002) All-solid-state supercapacitor using Nafion ${ }^{\circledR}$ polymer membrane and its hybridization with a direct methanol fuel cell. J Power Sources 109:500-506

32. Jarvis LP, Atwater TB, Cygan PJ (1999) Fuel cell/electrochemical capacitor hybrid for intermittent high power applications. J Power Sources 79:60-63

33. Payman A, Pierfederici S, Meibody-Tabar F (2008) Energy control of supercapacitor/fuel cell hybrid power source. Energy Convers Manage 49:1637-1644

34. Yu Z, Zinger D, Bose A (2011) An innovative optimal power allocation strategy for fuel cell, battery and supercapacitor hybrid electric vehicle. J Power Sources 196:2351-2359

35. Rodatz P, Paganelli G, Sciarretta A, Guzzella L (2005) Optimal power management of an experimental fuel cell/supercapacitorpowered hybrid vehicle. Control Eng Pract 13:41-53

36. Keskinen J, Sivonen E, Bergelin M, Eriksson J-E, Sjoberg-Eerola P, Valkiainen M, Smolander M, Vaari A, Uotila J, Boer H, 
Tuurala S (2010) Printed supercapacitor as hybrid device with an enzymatic power source. Adv Sci Technol 72:331-336

37. Conway BE (1999) Electrochemical supercapacitors: scientific fundamentals and technological applications. Springer, Berlin, pp 1-8

38. Frackowiak E, Beguin F (2002) Electrochemical storage of energy in carbon nanotubes and nanostructured carbons. Carbon 40:1775-1787

39. Trasatti S, Kurzweil I (1994) Electrochemical supercapacitors as versatile energy stores. Platinum Metals Rev 38:46-56

40. Simon P, Gogotsi Y (2008) Materials for electrochemical capacitors. Nat Mat 7:845-854

41. Lufrano F, Staiti P (2004) Performance improvement of Nafion based solid state electrochemical supercapacitor. Electrochim Acta 49:2683-2689

42. Arbizzani C, Biso M, Cericola D, Lazzari M, Soavi F, Mastragostino M (2008) Safe, high-energy supercapacitors based on solvent-free ionic liquid electrolytes. J Power Sources 185:1575-1579

43. Bichat MP, Raymundo-Pinero E, Beguin F (2010) High voltage supercapacitor built with seaweed carbons in neutral aqueous electrolyte. Carbon 48:4351-4361

44. Ruch PW, Kotz R, Wokaun A (2009) Electrochemical characterization of single-walled carbon nanotubes for electrochemical double layer capacitors using non-aqueous electrolyte. Electrochim Acta 54:4451-4458

45. Skunik M, Chojak M, Rutkowska IA, Kulesza PJ (2008) Improved capacitance characteristics during electrochemical charging of carbon nanotubes modified with polyoxometallate monolayers. Electrochim Acta 53:3862-3869
46. Gomez-Romero P, Chojak M, Cuentas-Gallegos K, Asensio JA, Kulesza PJ, Casan-Pastor N, Lira-Cantu M (2003) Hybrid organic-inorganic nanocomposite materials for application in solid state electrochemical supercapacitors. Electrochem Commun 5:149-153

47. Khomenko V, Frackowiak E, Beguin F (2005) Determination of the specific capacitance of conducting polymer/nanotubes composite electrodes using different cell configurations. Electrochim Acta 50:2499-2506

48. Zheng JP, Cygan PJ, Jow TR (1995) Hydrous ruthenium oxide as an electrode material for electrochemical capacitors. J Electrochem Soc 142:2699-2703

49. Rola B, Karaskiewicz M, Majdecka D, Mazur I, Bilewicz R, Ohga S, Rogalski J (2013) Scale up of Cerrena unicolor laccase production. J Agric Fac Kyushu Univ 58(2):231-238

50. Zelechowska K, Stolarczyk K, Lyp D, Rogalski J, Roberts KP, Bilewicz R, Biernat JF (2013) Aryl and $N$-arylamide carbon nanotubes for electrical coupling of laccase to electrodes in biofuel cells and biobatteries. Biocyber Biomed Eng 33(4):235-245

51. Shin W, Lee J, Kim Y, Steinfink H, Heller A (2005) Ionic conduction in $\mathrm{Zn}_{3}\left(\mathrm{PO}_{4}\right)_{2} \cdot 4 \mathrm{H}_{2} \mathrm{O}$ enables efficient discharge of the zinc anode in serum. J Am Chem Soc 127:14590-14591

52. Liang P, Huang X, Fan M-Z, Cao X-X, Wang C (2007) Composition and distribution of internal resistance in three types of microbial fuel cells. Appl Microbiol Biotechnol 77:551-558

53. Aiping Y, Chabot V, Zhang J (2013) Supercapacitors for energy storage and delivery, fundamentals and applications. CRC Press, Boca Raton 